\title{
I WANT TO SWING ON THAT SWING NEXT TO YOU
}

and tilt my head so far back

that my hair touches the ground

I want to talk about the past

I mean all the way back to the dinosaurs

and wonder why we grew

more than one cell

and sit here

in the starlight

and wait for the meteorite

96

because it's coming and it's going

to change everything

and I want to sit here in the darkness

with my body as a window

showing pictures of

people walking here and there

and living

like an explosion

layers of fire

a cannonball

a dahlia

I want to pull you into this water

and hold you under

until you smile

and see mermaids

and male sea horses 
giving birth

squeeze you so hard it makes a bruise fragile pushing into fragile

then light a candle

in a paper lantern

watch it rise into the night

and burn itself to pieces 